\title{
A bullous rash and bilateral hilar lymphadenopathy
}

\author{
D K L Lee, N N Chan
}

A 61-year-old Caucasian woman presented with a 4-day history of an acute blistering rash over her arms and legs. She had also developed swelling and puffiness around her eyes with associated vomiting and fever. She had been completely well up to 4 days prior to presentation. Her only medication was bendrofluazide $2.5 \mathrm{mg}$ daily for her long-standing hypertension. She had never smoked and reported no previous skin conditions, allergies or recent travel.

On examination, she looked unwell and was pyrexial at $38.3^{\circ} \mathrm{C}$. She had bilateral peri-orbital oedema and palpable supraclavicular lymph nodes. There were raised tender erythematous plaques, associated with tense blisters on some lesions, on her legs (figure 1), arms and face. Larger bullae were found on her forearms and upper back (figure 2). There were no nail changes or oral lesions. She had a regular tachycardia of 100 beats/min and a blood pressure of $120 / 60 \mathrm{mmHg}$. The rest of the examination was unremarkable.

Investigations showed a haemoglobin of $10.9 \mathrm{~g} / \mathrm{dl}$, a white cell count of $15.9 \times 10^{9} / 1$ (neutrophils $85 \%$ ), an erythrocyte sedimentation rate (ESR) of $81 \mathrm{~mm} / \mathrm{h}$ and a C-reactive protein of $132 \mathrm{mg} / 1$. Her throat and skin swabs and blood cultures were negative. Her chest X-ray (figure 3) revealed bilateral hilar lymphadenopathy.

Department of Medicine, St George's Hospital, London SW17 0QT, UK

D K L Lee

Department of Endocrinology, Charing Cross Hospital, London W6 8RF, UK N N Chan

Correspondence to Dr D K L Lee, c/o Dr N N Chan, EURODIAB, University College London, London WC1E 6BT, UK

Accepted 20 April 1999

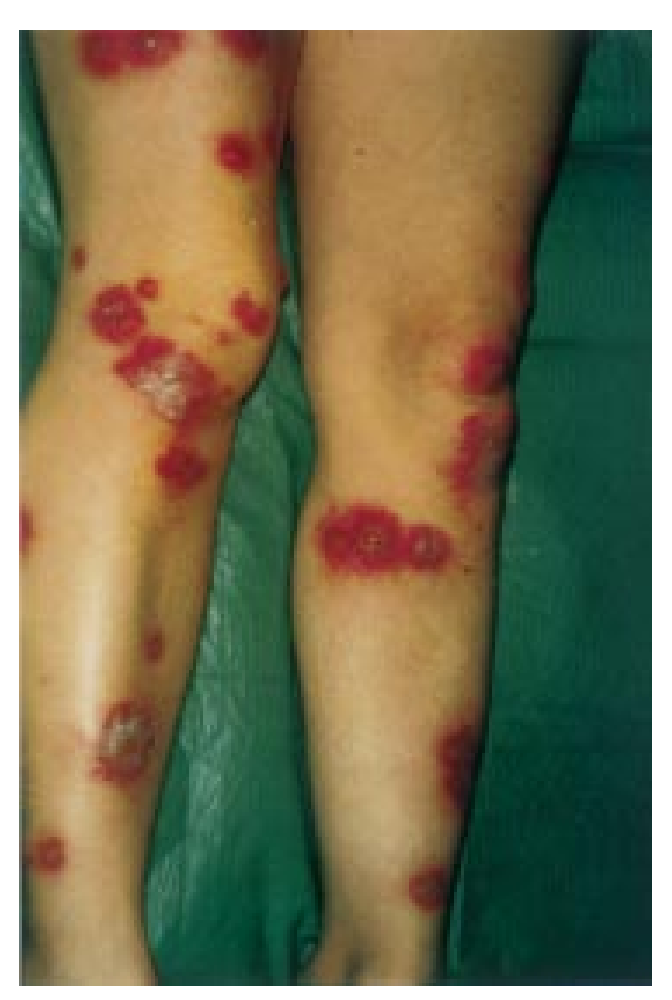

Figure 1 A photograph of the patient's legs (reproduced with her permission)

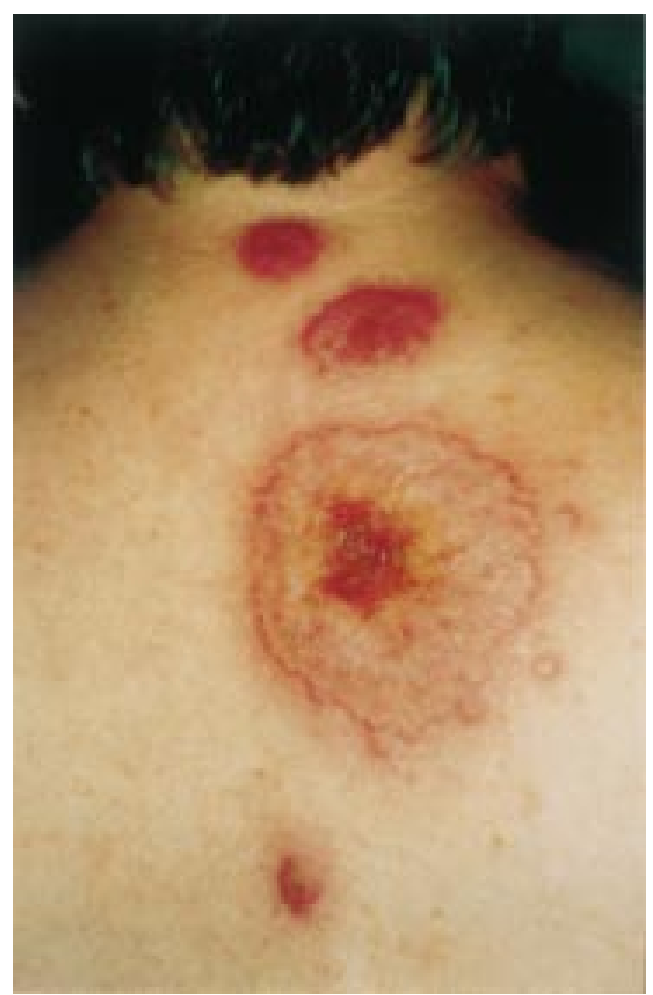

Figure 2 A photograph of the patient's upper back (reproduced with her permission) 


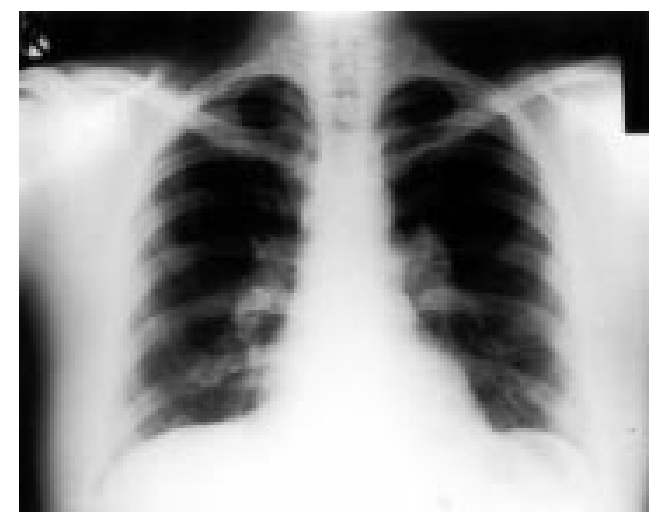

Figure 3 Chest X-ray

\section{Questions}

1 What is the most likely dermatological diagnosis? Give possible differential diagnoses.

2 What are the recognised associations?

3 How would you confirm the underlying diagnosis? 
Answers

QUESTION 1

The most likely dermatological diagnosis is an acute febrile neutrophilic dermatosis (Sweet's syndrome). The differential diagnoses include erythema multiforme, bullous pyoderma gangrenosum and bullous pemphigoid. In early non-blistering presentations, systemic lupus erythematosus would be an important differential diagnosis. In this case, a skin biopsy showed the typical features of Sweet's syndrome. There was a massive band-like infiltrate in the mid-dermis with numerous neutrophils. The infiltrate was predominantly peri-vascular with no significant leukocytoclastic vasculitis.

QUESTION 2

Approximately $25 \%$ of cases of Sweet's syndrome are associated with para-inflammatory or paraneoplastic disorders. ${ }^{1}$ About $2 \%$ of cases are associated with pregnancy. ${ }^{1}$ Examples of the recognised associations with Sweet's syndrome are given in box $1 .^{1-8}$

\section{QUESTION 3}

The severity of the cutaneous lesions of the presenting Sweet's syndrome and the patient's age and anaemia (see Discussion) point towards a possible associated malignancy. In view of the history, palpable lymph nodes and bilateral hilar lymphadenopathy, Hodgkin's lymphoma is the probable underlying diagnosis. The differential diagnosis includes bronchogenic carcinoma, pulmonary tuberculosis and sarcoidosis. A lymph node biopsy is therefore the most useful confirmatory investigation followed by computed tomography (CT) of the thorax.

The patient was initially treated with intravenous broad-spectrum antibiotics and prednisolone $60 \mathrm{mg}$ daily. She became apyrexial over the next 4 days and her skin lesions resolved over the next 2 weeks. Hodgkin's lymphoma was confirmed on her lymph node biopsy. CT scan showed stage II disease and she had a good response to her subsequent treatment with radiotherapy.

\section{Discussion}

Acute febrile neutrophilic dermatosis was first described in 1964 by Robert Douglas Sweet from the observation of the condition in eight female patients. ${ }^{2}$ This disease was subsequently termed Sweet's syndrome. Data on the incidence and prevalence of Sweet's syndrome is limited. A recent retrospective review by Bourke et al of six dermatological units in the UK revealed only 87 histologically proven cases in total. ${ }^{3}$ The pathogenesis of Sweet's syndrome has yet to be completely elucidated but it is generally accepted to be an immunemediated reaction. Classically, it occurs in middle aged women after a non-specific infection. It usually presents as a sudden eruption of

1 von den Driesch P. Sweet's syndrome. F Am Acad Dermatol 1994;31:535-48.
Associations with Sweet's syndrome

- idiopathic

- para-inflammatory: inflammatory bowel disease (eg, Crohn's disease, ulcerative colitis); infections (eg, yersinia, human immunodeficiency virus); autoimmune disorders (eg, lupus erythematosus)

- paraneoplastic: myeloproliferative disorders (eg, acute myeloid leukaemia); lymphoproliferative disorders (eg, Hodgkin's lymphoma); solid tumours (eg, adenocarcinoma, pelvic carcinoma)

- miscellaneous: pregnancy; drugs (eg, minocycline, granulocyte colony-stimulating factor)

Box 1

\section{Learning points}

- acute febrile neutrophilic dermatosis (Sweet's syndrome) is characterised by tender erythematous plaques or nodules occurring predominantly on the face, neck and extremities

- a raised ESR, leucocytosis and fever are often present

- Sweet's syndrome is associated with para-inflammatory and paraneoplastic disorders

- patients with Sweet's syndrome and an associated malignancy are more likely to have severe cutaneous lesions, an anaemia and be older

Box 2

tender erythematous plaques or nodules on the face, neck and extremities. Vesicobullous lesions occur less commonly. ${ }^{4}$ The onset of the rash is often associated with fever, a raised ESR and neutrophil leucocytosis. ${ }^{1-7}$ Arthritis or arthralgia and ophthalmic involvement can occur but lymphadenopathy is not a regular feature. The skin lesions often respond well to high-dose systemic corticosteroid therapy ${ }^{1-7}$ and usually heal without scarring. ${ }^{5}$ Alternative treatments include potassium iodide, tetracycline and immunosuppressive drugs. ${ }^{15}$ Sweet's syndrome recurs in about a quarter of cases. ${ }^{1}$

At least $10-20 \%$ of published cases of Sweet's syndrome occurred in patients with associated malignancy. ${ }^{13-7}$ The onset of Sweet's syndrome tends to coincide with or precede (up to 1 year) the diagnosis of malignancy in more than $60 \%$ of these patients. ${ }^{4}$ They are more likely to be older and to have severe cutaneous lesions and an anaemia. ${ }^{3}$ Recognition of these various presentations of Sweet's syndrome is useful in the light of its potentially serious associations.

\section{Final diagnosis}

Sweet's syndrome associated with Hodgkin's lymphoma.

Keywords: neutrophilic dermatoses; Sweet's syndrome; Hodgkin's lymphoma

2 Sweet RD. An acute febrile neutrophilic dermatosis. $\mathrm{Br} \mathcal{F}$ Dermatol 1964;74:349-56. 
3 Bourke JF, Keohane S, Long CC, et al. Sweet's syndrome Bourke JF, Keohane S, Long CC, et al. Sweet's syndrome and malignancy in the UK. Brf Dermatol 1997;137:609-13. Sweet's syndrome: review of the world literature. 7 Clin Sweet's syndrome: review

5 Lear JT, Atherton MT, Byrne JPH. Neutrophilic dermatoses: pyoderma gangrenosum and Sweet's syndrome. Postgrad Med F 1997;73:65-8.

6 Fett DL, Gibson LE, Su WP. Sweet's syndrome: systemic signs and symptoms and associated disorders. Mayo Clin Proc 1995;70:234-40.
7 Woodrow SL, Munn SE, Basarab T, et al. Sweet's syndrome in association with non-Hodgkin's lymphoma. Clin Exp Dermatol 1996;21:357-9.

8 Reuss-Borst MA, Muller CA, Waller HD. The possible role of G-CSF in the pathogenesis of Sweet's syndrome. Leuk Lymphoma 1994;15:261-4.

\title{
An elderly man with diarrhoea and cellulitis
}

\author{
M Hussien, M E L Ismail
}

A 73-year-old man was admitted with a 10-day history of diarrhoea. On examination he was apyrexial. His pulse rate was 90 beats/min and blood pressure $120 / 70 \mathrm{mmHg}$. His abdomen was soft with normal bowel sounds. Anal digitation was negative. He was found to have an area of marked cellulitis on the lateral aspect of the right groin (figure 1). By the evening of his admission this area became necrotic, he also became pyrexial and developed subcutaneous emphysema of the anterior abdominal wall and the right thigh (figures 2 and 3 ).

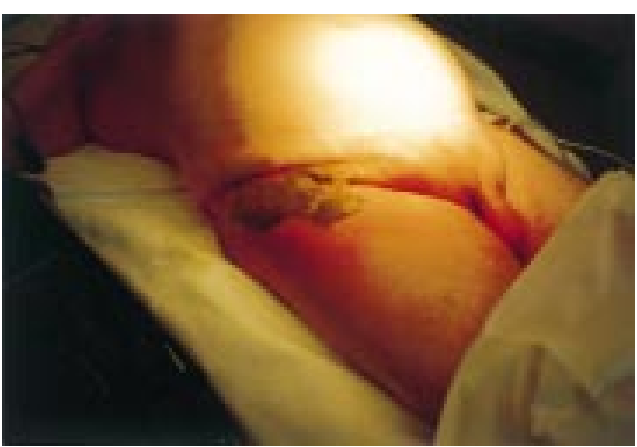

Figure 1 Fully developed abscess of the right groin

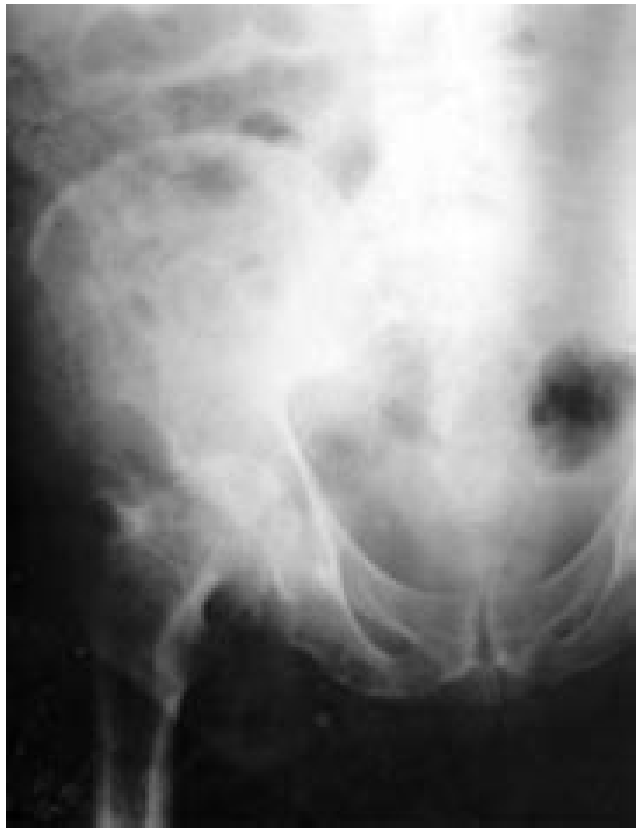

Figure 3 Plain X-ray showing emphysema of the right thigh and anterior abdominal wall

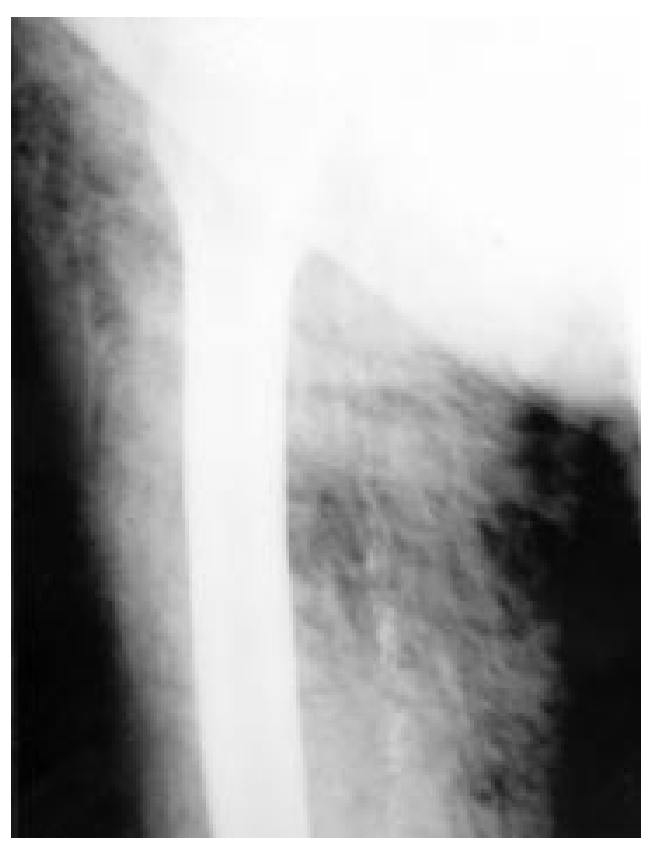

Figure 2 Plain X-ray showing emphysema of the right thigh

South Tyrone Hospital, Dungannon, Co Tyrone, N Ireland M Hussien

Downe Hospital, Downpatrick, Co Down, N Ireland BT30 6JA

M E L Ismail

Correspondence to Mr M Hussein, Surgical Department, Altnagelvin Area Hospital, Glenshan Road, Londonderry,
1 What is the probable diagnosis?

2 What other investigations would you consider? 


\section{Answers}

QUESTION 1

This is a case of perforated diverticular disease of the colon.

QUESTION 2

Sigmoidoscopy and X-ray contrast studies may aid in demonstrating the site and cause of perforation, however, the intra-abdominal pathologic characteristic can only be defined at operation ${ }^{2}$. Computed axial tomographic scan of the leg and abdomen may define the presence and nature of the intra-abdominal pathologic abnormality.

\section{Discussion}

A review of the literature has shown that gastrointestinal perforation may present with subcutaneous emphysema with or without abscess formation. ${ }^{2-5}$

The underlying pathology is usually a retroperitoneal perforation of a colorectal neoplasm

1 Mair WSJ, McAdam WAF, Lee PWR, Jepson K, Goligher JC. Carcinoma of the large bowel presenting as a subcutaneous abscess of the thigh: a report of 4 cases. $\mathrm{Br} F$ Surg 1997;64:205-9.

2 Rotstein O, Pruett TL, Simmons RL. Thigh abscess, an uncommon presentation of intra-abdominal sepsis. Am $\mathfrak{F}$ Surg 1986;151:414-8.

3 Haiart DC, Stevenson P, Hartley RC. Leg pain: an uncommon presentation of perforated diverticular disease. $f R$ Coll Surg Edin 1989;34:17-20. or diverticular disease; origin from the small bowel or appendix is distinctly less common. ${ }^{2}$ Routes of extension of infection into the thigh can be either direct through the subcutaneous tissue or through naturally occurring defects in the abdominal wall, including the psoas muscle, through the femoral canal, by the way of the obturator foramen, and through the sacrosciatic foramen. ${ }^{125}$

The condition has a high mortality rate. ${ }^{12}$ Treatment with wide local drainage and faecal diversion, together with the appropriate antibiotic therapy after vigorous resuscitation, remains the mainstay of surgical management.

\section{Final diagnosis}

Perforated diverticular disease of the colon.

Keywords: diverticular disease; diarrhoea; cellulitis; gastrointestinal perforation; emphysema

4 Oetting HK, Kramer NE, Branch WE. Subcutaneous emphysema of gastrointestinal origin. Am f Med 1955; $872-85$.

5 Ferrie BG, Smith IS. Subcutaneous emphysema of thigh secondary to diverticular disease. $f R$ Coll Surg Edin 1982;27:239-40. 


\title{
Pleural effusion and fever in a middle-aged Asian
}

\section{$\operatorname{man}$}

\author{
I Woolhouse, H Collinson, D Honeybourne, R E Ferner
}

A 66-year-old retired Asian steelworker was admitted with a 2-month history of breathlessness, productive cough and fever following a recent trip to India. He was an ex-smoker who denied previous exposure to tuberculosis or asbestos. On examination he had a fever of $38^{\circ} \mathrm{C}$ but no finger clubbing or lymphadenopathy. Clinically, he had signs consistent with a large right pleural effusion.

Investigations revealed an elevated plasma viscosity of $2.02 \mathrm{mPa}$ (normal 1.5-1.72), with a leucocytosis of $20.6 \times 10^{9} / 1$ (91\% neutrophils). Malaria screen was negative. Haemophilus influenzae was cultured from the sputum. Ziehl Neelsen stain was negative, as was cytology for malignant cells. The pleural fluid was a sterile exudate. Histology from pleural biopsy revealed inflammatory material, mainly neutrophils and fibrin. No granulomata or malignancy were identified. His chest X-ray, thoracic computed tomography (CT) scan, and bronchoscopy are shown in figures 1, 2 and 3 , respectively. ${ }^{3}$

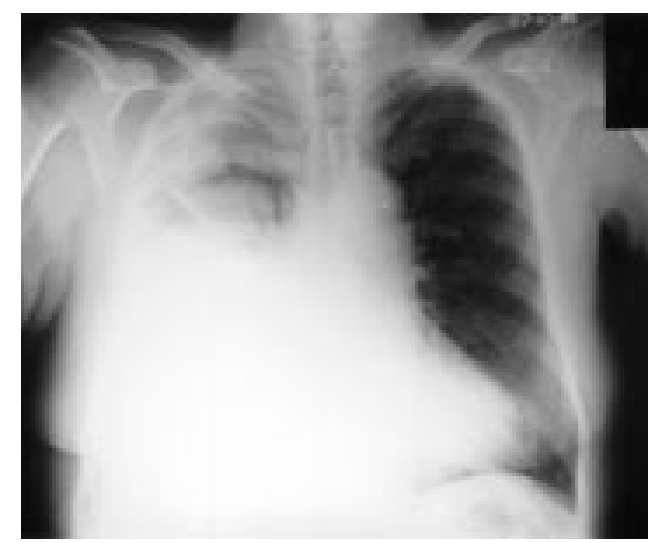

Figure 1 Chest X-ray

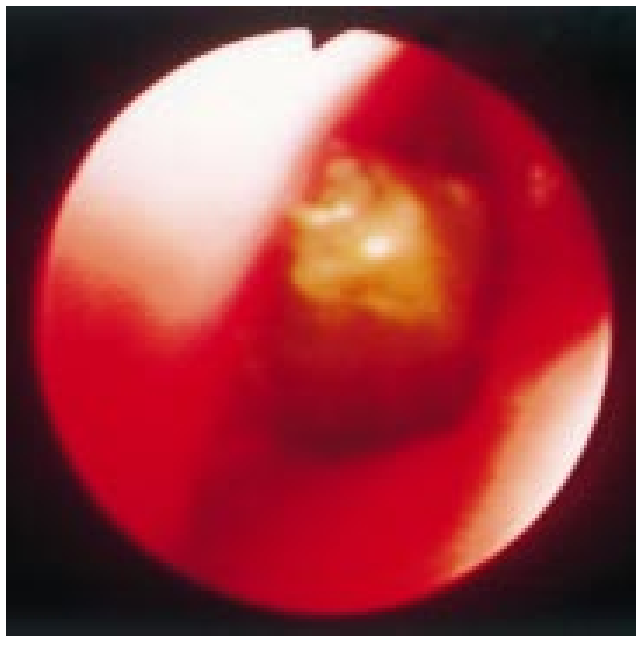

Figure 3 Bronchoscopic appearance

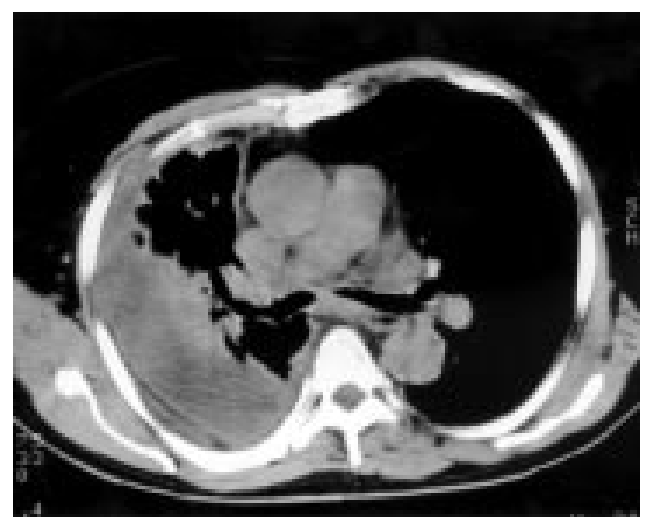

Figure 2 Thoracic CT scan
Department of

Medicine, City

Hospital, Birmingham

B18 7QH, UK

I Woolhouse

$\mathrm{H}$ Collinson

D Honeybourne

R E Ferner

Correspondence to Dr RE Ferner

Accepted 16 April 1999 
Answers

QUESTION 1

The chest X-ray shows a large right pleural effusion. The CT scan shows thickening of the parietal pleura in the lower right chest and a loculated pleural effusion. There is also narrowing of the right lower lobe bronchus and one enlarged tracheal lymph node.

QUESTION 2

In this case the main differential diagnosis lies between pulmonary tuberculosis and bronchial carcinoma. However, a Haemophilus influenzae pneumonia with a parapneumonic effusion could also produce a similar picture, although the history is rather prolonged for this. Neoplastic causes other than carcinoma should be excluded, such as lymphoma and mesothelioma, as should chronic inflammatory disorders such as connective tissue disease and sarcoidosis. Finally, even though there is no history of choking, this clinical picture can be seen following foreign body aspiration.

QUESTION 3

The bronchoscopic appearance is that of a foreign body in the right lower lobe bronchus. This was removed and identified as a cardamom pod (Elettaria cardamomum). The diagnosis was therefore confirmed as silent tracheobronchial foreign body aspiration resulting in bronchial obstruction, distal pneumonitis and pleural effusion.

Six months later he had made a complete recovery and his chest $\mathrm{X}$-ray had returned to normal.

\section{Discussion}

Inhalation of foreign bodies into the bronchial tree is well recognised as a cause of both acute and chronic respiratory symptoms in children, but less so in adults. ${ }^{1}$ Those at particular risk include the elderly and alcoholics. Aspiration is also more likely to occur in those patients with neurological disease associated with an im-

1 Limpar AH, Prakash UBS. Tracheobronchial foreign bodies in adults. Ann Intern Med 1990;112:604-9.

Weissberg D, Schwartz I. Foreign bodies in the tracheobronchial tree. Chest 1987;91:730-3.

3 Ben-Dov, Aelony Y. Foreign body aspiration in the adult: an occult cause of chronic respiratory symptoms. Postgrad Med $f$ 1989;65:299-301.

\section{Learning points}

- silent foreign body aspiration can occur in all patients, not just those with an impaired swallowing reflex

- presentation can be wide and varied therefore foreign body aspiration should be considered as a potential cause of subacute or chronic respiratory symptoms

- bronchoscopy usually allows both diagnosis and treatment

paired swallowing or cough reflex, but it can still occur in people without these problems, for example, rapid or careless eaters. ${ }^{2}$ Food items are most commonly aspirated and they tend to cause more irritation to the bronchial mucosa than inorganic matter because of the oils they release.

Presenting features of unrecognised aspiration can include persistent pneumonia, asthma, chronic cough with haemoptysis, lung abscess, bronchiectasis and pleural effusion. ${ }^{3}$ There are no previous reports of this condition mimicking pulmonary tuberculosis as in our case. Diagnosis can be difficult as the patient is often unaware of aspiration or unable to give a clear history. Delay in diagnosis can therefore be considerable and previously it has been reported to have taken as long as 40 years. ${ }^{4}$

Once the diagnosis of foreign body aspiration is considered, it can usually be confirmed and removal performed by fibre-optic bronchoscopy. If this method is unsuccessful then rigid bronchoscopy or thoracotomy may be required.

\section{Final diagnosis}

Silent tracheobronchial foreign body aspiration resulting in bronchial obstruction, distal pneumonitis and pleural effusion.

Keywords: foreign body aspiration; tracheobronchial tree

4 Thomas V, Chandy G, Rolston DD. Foreign body in the lung, years without symptoms. Br F Dis Chest 1986;80:292- 


\title{
Recurrent proptosis and thyroid eye disease
}

\author{
Anthony S L Kwan, Elizabeth Wilkinson, Gillian G W Adams
}

A 58-year-old Caucasian woman presented to our hospital with a 2-week history of diplopia and proptosis of the left eye. Ten years earlier, she had been diagnosed as having ophthalmic Graves' disease and subsequently underwent successful left transantral orbital decompression for optic nerve compression. On clinical examination, there was bilateral proptosis, $5 \mathrm{~mm}$ greater on the left side, and hypoglobus of the left eye. Her visual acuities and colour vision were normal (Snellen visual acuity: left $6 / 6$, right $6 / 6$ ). There was significant restriction of ocular movements in the left eye. Routine haematological tests were performed, including thyroid function, which were all normal. A computed tomographic (CT) scan of the orbits was performed (figures 1 to 5).

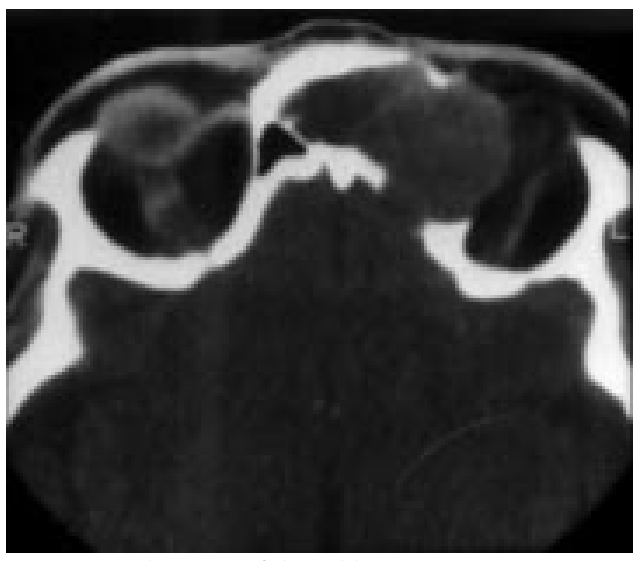

Figure 1 CT scan of the orbits

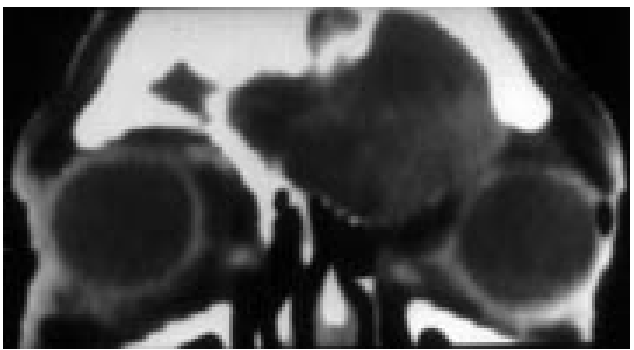

Figure 2 CT scan of the orbits

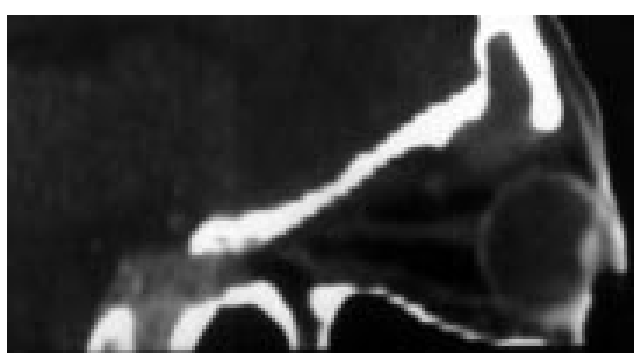

Figure 3 CT scan of the orbits

\section{Questions}

1 What are the differential diagnoses of unilateral proptosis in this case?

2 What are the symptoms of orbital disease?

3 What are the causes of visual impairment in orbital disease?

4 What do the CT scans show?

5 How common is recurrent proptosis after orbital decompression in thyroid eye disease? 


\section{Answers}

QUESTION 1

The most likely causes are mucocele or recurrent thyroid eye which are specific to this case. Other causes of proptosis include axial causes (orbital varices, caroticocavernous fistulas, optic nerve gliomas, cavernous haemangioma, meningiomas and orbital pseudotumours, eg, lymphoma) and non-axial causes (dermoid cysts in children or young adults, neurofibromatosis in children, lacrimal tumours, mucocele or carcinomas of sinuses (ethmoidal and frontal), meningoencephalocele, and rhabdomyosarcomas in children).

QUESTION 2

The symptoms of orbital disease are proptosis, globe displacement, lid retraction, diplopia, visual impairment, pain, reduced sensation of the ophthalmic and maxillary branches of the trigeminal nerve and bruit.

\section{QUESTION 3}

The causes of visual impairment in orbital disease are optic nerve compression, corneal exposure, pseudohypermetropia, visual field loss, and choroidal folds.

QUESTION 4

The CT scans demonstrate, on the left side, a mucocele extending from the ethmoidal sinus through the bony defect formed by previous decompression, into the orbit causing exophthalmos (figure 1) and hypoglobus (figure 2). The mucocele extended up to the frontal sinus (figure 3). The involvement of ethmoidal sinus (figure 4) and frontal sinus (figure 5) is extensive.

QUESTION 5

Recurrent proptosis after orbital decompression in patients with Graves' disease is extremely rare and is a diagnosis of exclusion (see Discussion).

\section{Outcome}

The patient was referred to an ear, nose and throat surgeon for further management with a view to removing the mucocele endoscopically. The patient declined and the mucocele has remained stable and has not increased in size to date.

\section{Discussion}

Orbital decompression is a well recognised treatment for severe dysthyroid eye disease. Its main indications are optic nerve compression, severe corneal exposure and cosmesis. Removal of the orbital wall during decompression allows excessive orbital fat to herniate through the opening thus relieving the intra-orbital pressure. Long-term results of decompression are encouraging and few complications are seen which include diplopia, meningitis, sinusitis and cerebrospinal fluid leak. ${ }^{1-3}$

Graves' orbitopathy is thought to be a disease with a self-limiting time course of 1 to
5 months. ${ }^{5}$ True recurrence of orbitopathy has not been reported in the literature. The closest report of a 'recurrence' is the enlargement of extra-ocular muscle after orbital decompression. ${ }^{4}$ Any 'recurrence' should be treated with suspicion. In this case, a mucocele originated from the frontoethmoidal sinus extended into the orbit through an iatrogenic opening following a transantral orbital decompression. To our knowledge this has not been previously reported.

Patients with frontoethmoidal mucocele are often asymptomatic. Some of the presenting symptoms include sinusalgia, facial heaviness, epiphora (from lacrimal drainage impairment), swelling of medial orbitofrontal region, globe displacement, diplopia, infection of the mucocele, and rarely nasal obstruction and rhinorrhea. The classical sign is 'egg shell cracking' or fluctuation on palpation over the frontal sinus due to thinning of bone over the mucocele. Other signs include discharging fistula and proptosis. In terms of investigations, X-ray may show an overall loss of translucence of the affected side and a loss of the scalloped bony margin if the vertical portion of the frontal sinus is affected. CT scan may show the accompanying bone changes and the affected area often has a homogenous appearance which is isodense to the brain tissue. Magnetic resonance imaging is specific and shows a high signal obtained on the $\mathrm{T}_{2}$-weighted spin-echo sequences (except in old lesions where these signals become dark) and a low signal on inversion recovery. Treatment for all forms of mucocele is surgical. Current practice favours endoscopic surgical marsupialisation. ${ }^{6}$ In some cases of frontal mucocele, an external approach (external frontoethmoidectomy) is required with an osteoplastic flap procedure or even sometimes bone grafts, depending on the degree of sinus expansion and bone destruction. $^{7}$ The aim is to leave the sinus intact, remove the mucocele lining but avoid stripping too much mucosa and thereby allowing the reconstitution of a well-drained sinus cavity. Occasionally, to improve drainage, the intersinus septum is perforated to unite the two frontal sinuses or the sinus is canalised with a fenestrated Silastic tube into the nasal cavity. When there is mucosal degeneration or the posterior wall of the frontal sinus is dehiscent on the dura, sinus obliteration or sinus cranialisation should be used.

In the light of this case, we recommend that all patients with a recurrence of orbital symptoms following orbital decompression in Graves' orbitopathy should undergo thorough investigation, including a repeat CT scan, to exclude such complications.

\section{Final diagnosis}

Frontoethmoidal mucocele following orbital decompression.

Keywords: Graves' orbitopathy; orbital decompression; frontoethmoidal mucocele 
1 Garrity JA, Fatourechi V, Bergstralh EJ, et al. Results of transantral orbital decompression in 428 patients with severe Graves' ophthalmopathy. Am f Ophthalmol 1993;116 533-47.

2 Hutchison BM, Kyle PM. Long-term visual outcome following orbital decompression for dysthyroid eye disease. Eye 1995;9:578-81.

3 Warren JD, Spector JG, Burde R. Long-term follow-up and recent observations on 305 cases of orbital decompression for dysthyroid orbitopathy. Laryngoscope 1989;99:35-40.

4 Wenz R, Levine MR, Putterman A, Bersani T, Feldman K Extraocular muscle enlargement after orbital decompres- sion for Graves' ophthalmopathy. Ophthalmol Plast Reconstr Surg 1994;10:34-41.

5 Duke-Elder S. System of ophthalmology, vol 13. St Louis: CV Mosby, 1974.

6 Lund VJ. Endoscopic management of paranasal sinus mucocoeles. F Laryngol Otol 1998;112:36-40

7 Iannetti G, Cascone P, Valentini V, Agrillo A Paranasal sinus mucocele: diagnosis and treatment. 7 Craniofac Surg 1997;8:391-8.

\title{
A man presenting with limb weakness and electrolyte imbalance
}

\author{
J C Smith, C Meehan, P Lyons, A M Robinson
}

A 39-year-old man presented with lower limb muscle pains and weakness which had progressed rapidly over the preceding 2 weeks. Immediately prior to hospital admission he was unable to stand unaided. There had been no disturbance of bulbar, sensory or sphincter function and he reported no recent gastrointestinal symptoms. Medical history included colitis, which was quiescent. His only regular medication was olsalazine. On examination, he was normotensive (and remained so throughout his admission). There was no rash. Cardiovascular, respiratory and abdominal examinations were normal. Neurological examination revealed generalised weakness in all four limbs, most marked proximally. Tendon reflexes were preserved. Plantar response was flexor. Examination of cranial nerves was normal.

Laboratory investigations revealed a serum potassium of $1.8 \mathrm{mmol} / 1$. Serum sodium, urea and creatinine were within normal limits. Creatine kinase was $10719 \mathrm{IU} / \mathrm{l}$. A quadriceps muscle biopsy was performed and the histology is shown in figure 1. Further investigations included an abdominal ultrasound scan, following which computed tomography (CT) of the abdomen was performed (figure 2). A 24-hour urine collection for catecholamines was undertaken (table).

Royal United Hospital, Bath, UK

Department of

Medicine

J C Smith

A M Robinson

Department of

Pathology

C Meehan

Department of

Neurology

P Lyons

Correspondence to

Dr Jamie Smith, Research

Fellow, Department of

Endocrinology, Diabetes and

Metabolism, A7 Office,

University Hospital of Wales,

Heath Park, Cardiff CF4

$4 \mathrm{XN}$, UK

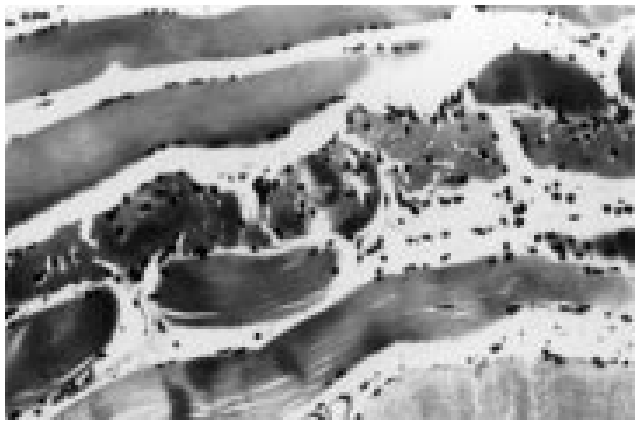

Figure 1 Quadriceps muscle biopsy

Table Levels of free catecholamines (laboratory normal in brackets)

\begin{tabular}{ll}
\hline Catecholamine \\
\hline Noradrenaline $(\mathrm{nmol} / 24 \mathrm{~h})$ & $3328(<800)$ \\
Adrenaline $(\mathrm{nmol} / 24 \mathrm{~h})$ & $725(<100)$ \\
Dopamine $(\mathrm{nmol} / 24 \mathrm{~h})$ & $>45000(<3100)$ \\
\hline
\end{tabular}

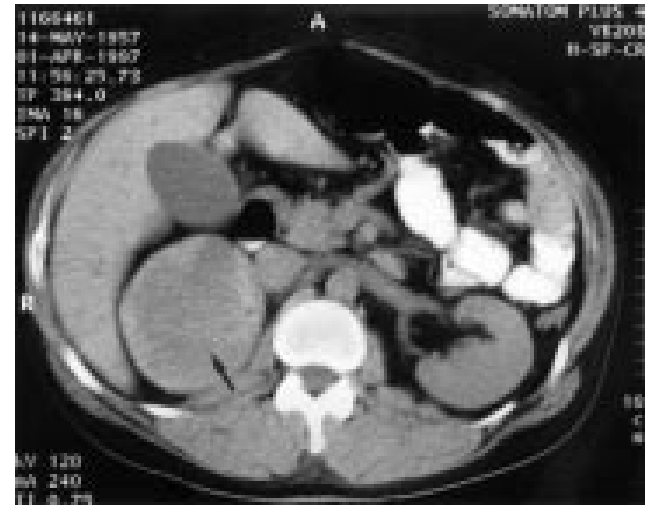

Figure 2 CT scan

\section{Questions}

1 What does the CT scan show?

2 What is the likely underlying diagnosis?

3 What are the three most common presenting symptoms for this condition?

4 What caused the muscular signs and symptoms? 
Answers

QUESTION 1

The CT scan (figure 2) shows a large mass (arrow) arising from the region of the right adrenal gland. It has displaced the liver and kidney on that side. The contralateral adrenal is just visible anterior to the left kidney. The appearances are therefore compatible with an adrenal tumour.

QUESTION 2

The 24-hour urinary collection shows significantly elevated levels of noradrenaline, adrenaline and dopamine. These three catecholamines are the dominant secretory products of phaeochromocytomas. In this case, the dopamine levels are grossly elevated and predominate. These biochemical findings by themselves suggest the presence of a phaeochromocytoma which, in view of the CT findings, is likely to have an adrenal origin.

QUESTION 3

Phaeochromocytomas are well known for their diverse clinical presentation and manifestations. The three most common presenting symptoms, which classically occur in intermittent episodes or 'attacks', are headache $(60 \%$ of cases), sweating (52\%) and palpitations $(49 \%) .{ }^{1}$ Hypertension is constant in only about $50 \%$ of patients, paroxysmal in about $30 \%$ and absent in approximately $20 \%$.

QUESTION 4

Generalised muscle weakness associated with a markedly elevated creatine kinase suggests widespread muscle injury. The histology from the muscle biopsy (figure 1) shows scattered myofibre necrosis with no evidence of inflammation or vasculitis. These appearances are consistent with rhabdomyolysis. Muscle damage has been known to occur in association with phaeochromocytoma, with previous reports postulating that ischaemic muscle injury results from catecholamine-mediated vasoconstriction. ${ }^{2}$ However, the direct cause in this case is likely to be hypokalaemia. Marked potassium depletion impairs striated muscle function, causing weakness typically affecting shoulder and pelvic girdle musculature. When hypokalaemia is severe $(<2.5 \mathrm{mmol} / \mathrm{l})$ or prolonged, a full blown hypokalaemic myopathy may develop, leading to myositis or frank rhabdomyolysis. ${ }^{3}$

\section{Discussion}

This case illustrates an unusual presentation of a catecholamine-secreting tumour. The patient developed a reversible hypokalaemic myopathy as a direct result of the tumour. This myopathy resolved following the restoration of normokalaemia using potassium supplementation. It is likely that the hypokalaemia arose as a direct result of the tumour. Phaeochromocytomas arise from chromaffin cells which belong to the APUD (amine precursor uptake decarboxylase) series of cells. These cells are capable of co-secreting other peptide hormones whose

\section{Learning points}

- clinical manifestations of phaeochromocytoma can be diverse and may reflect the type of predominant catecholamine as well as other peptide hormones potentially secreted by the tumour

- tumours secreting predominantly dopamine often present without hypertension and sometimes cause hypotension

- severe hypokalaemia can cause neuromuscular symptoms and may lead to muscle necrosis and rhabdomyolysis

- high levels of circulating catecholamines can cause hypokalaemia by ionic shift. This phenomenon can also occur after exposure to beta agonists

effects can confuse the diagnosis and contribute to the diverse clinical manifestations seen with phaeochromocytomas. Hypokalaemia could result from the actions of such hormones. Adrenocorticotropin can, for example, be secreted, producing hypercortisolism ${ }^{4}$ and similarly, vasoactive intestinal peptide secretion can cause a syndrome of watery diarrhoea associated with gastrointestinal potassium loss. Catecholamines, particularly adrenaline, can also directly cause hypokalaemia of physiological importance through stimulation of beta 2 receptors causing activation of sodiumpotassium-ATPase in skeletal muscle and subsequent ionic shift of potassium. ${ }^{5}$ This is thought to be the mechanism responsible for hypokalaemia occurring during acute myocardial infarction when levels of circulating adrenaline are high.

Another unusual feature of this case was the complete absence of hypertension, despite a tumour producing high levels of catecholamines. The symptoms and signs associated with phaeochromocytoma are largely related to the amount and type of catecholamine synthesised and released by the tumour. Noradrenaline, adrenaline and dopamine each have differing pharmacological effects. Noradrenaline secretion is associated with systolic and diastolic hypertension but also shrinkage of the plasma volume with a resultant rise in the haematocrit and the development of postural hypotension. Adrenaline-secreting tumours stimulate beta-adrenoceptors leading to tachycardia, cardiac arrhythmias and metabolic effects including glycogenolysis and lipolysis. Predominantly dopamine-secreting tumours are characteristically associated with an absence of hypertension and sometimes produce hypotension by counteracting the vasoconstricting effects of noradrenaline, as well as producing vasodilatation in renal and mesenteric vasculature. ${ }^{6}$ These factors are likely to explain the absence of hypertension in this particular case. All clinical and biochemical abnormalities resolved following surgical removal of the tumour. 
Final diagnosis

Phaeochromocytoma presenting with hypokalaemic rhabdomyolysis.

1 Ross EJ, Griffith DNW. The clinical presentation of phaeochromocytoma. Q f Med 1989;266:485-96.

2 Bhatnagar D, Carey P, Pollard A. Focal myositis and elevated creatine kinase levels in a patient with phaeochromocytoma. Postgrad Med F 1986;62:197-8.

3 Van Horn G, Drori JB, Schwartz FD. Hypokalemic myopathy and elevation of serum enzymes. Arch Neurol 1970; 22:335-41.

4 O'Brien T, Young Jr WF, Davila DG, et al. Cushing's syndrome associated with ectopic production of
Keywords: phaeochromocytoma; hypokalaemia; rhabdomyolysis

All India Institute of Medical Sciences, 110029 New Delhi, India

Department of

Medicine

U Kumar

P Aggarwal

R Handa

J P Wali

Department of

Haematology

R Saxena

Correspondence to

Praveen Aggarwal

Accepted 19 April 1999

\section{Central cyanosis in a young man}

Uma Kumar, Praveen Aggarwal, Rohini Handa, Renu Saxena, Jyoti Prakash Wali

A 25-year-old man presented with bluish discoloration of body, lips and nails since birth. He denied any other significant complaints. General examination revealed presence of central cyanosis with steel-grey complexion of the body. He did not have clubbing of nails. Systemic examination was unremarkable. Investigations showed a haemoglobin of $17.2 \mathrm{~g} / \mathrm{dl}$ and a normal blood chemistry. The arterial blood gas analysis while the patient was breathing room air revealed a $\mathrm{PaO}_{2}$ of $100.9 \mathrm{mmHg}$ and an oxygen saturation of $97.8 \%$.

\section{Questions}

1 What is the probable diagnosis?

2 What are the common causes of central cyanosis?

3 How would you approach a patient with central cyanosis?

4 What is the appropriate management in the present case? 


\section{Answers}

QUESTION 1

As this patient had central cyanosis since birth and was asymptomatic, the probable diagnosis is congenital methaemoglobinaemia. This diagnosis is supported by a normal arterial blood gas analysis.

QUESTION 2

A number of cardiac and pulmonary diseases can produce central cyanosis (box 1). Rarely, central cyanosis is produced by disorders of haemoglobin.

QUESTION 3

Duration of cyanosis (cyanosis present since birth is usually due to congenital heart disease or methaemoglobinaemia), symptoms related to cardiovascular and pulmonary systems, and exposure to drugs or chemicals that may produce methaemoglobinaemia are important points in the history of a patient who presents with central cyanosis. Central cyanosis should be differentiated from peripheral cyanosis, as the tongue is spared in the latter condition. Clubbing, and any abnormality in cardiac and pulmonary systems should be looked for. Clubbing with cyanosis is present in patients with congenital cyanotic heart diseases, and occasionally in patients with pulmonary diseases such as lung abscess or pulmonary arteriovenous shunts. Chest radiograph, electrocardiograph and echocardiograph may be obtained if there are any suggestions of pulmonary or cardiovascular diseases on history and examination. If there is no evidence of cardiopulmonary disease, a diagnosis of methaemoglobinaemia should be considered.

Pulse oximetry may be helpful in detecting methaemoglobinaemia. Pulse oximeter meas-

\begin{tabular}{|l|}
\hline Causes of central cyanosis \\
\hline Reduced arterial oxygen saturation: \\
- high altitude \\
- disorders of central respiratory drive (bulbar \\
poliomyelitis, encephalitis, brainstem \\
haemorrhage or infarction, CNS depressants, \\
primary hypoventilation) \\
- disorders of respiratory musculoskeletal system \\
(cervical cord injury, poliomyelitis, motor \\
neurone disease, myasthenia gravis, muscular \\
dystrophy, flail chest, tension pneumothorax, \\
kyphoscoliosis, morbid obesity) \\
- disorders of gas exchange (severe bronchial \\
asthma, chronic obstructive airway disease, \\
foreign body inhalation, obstructive sleep \\
apnoea, malfunctioning ventilators, pulmonary \\
oedema, interstitial lung disease) \\
- anatomic shunts (cyanotic congenital heart \\
diseases, pulmonary arteriovenous fistulas) \\
- haemoglobin with low affinity for oxygen (Hb \\
Kansas) \\
Haemoglobin abnormalities: \\
- methaemoglobinaemia \\
- sulphaemoglobinaemia \\
\hline
\end{tabular}

Box 1 ures the light absorbance changes by arterial pulsations at only two wavelengths, one in the red $(660 \mathrm{~nm})$ and the other in the near infrared $(940 \mathrm{~nm})$ range. Methaemoglobin has a high absorbance at both wavelengths, tending to drive the ratio of absorbance toward 1, which corresponds to an oxygen saturation of nearly $85 \%$. Hence, with a high level of methaemoglobin in the blood, pulse oximeter readings will tend to be around $85 \%$. In contrast, the saturation as reported on an arterial blood gas is a calculated value based on the partial pressure of dissolved oxygen and assumes no abnormal haemoglobin is present. Therefore, the reported oxygen saturation from the laboratory is generally higher than that measured with a pulse oximeter. ${ }^{12}$ This difference is called the saturation gap and is typically more than $5 \%$ in patients with methaemoglobinaemia. Qualitative confirmation of methaemoglobinaemia is done by blood spectrophotometry. Once confirmed, electrophoresis of haemoglobin and estimation of methaemoglobin reductase are required to diagnose the cause of methaemoglobinaemia.

In the present case, the oxygen saturation measured by pulse oximetry was $90 \%$, and the oxygen saturation gap $7.8 \%$. Spectrophotometry of the haemolysate of the patient's blood revealed a methaemoglobin band at $630 \mathrm{~nm}$. On quantification estimation, methaemoglobin was found to be $30 \%$. Electrophoresis of the haemoglobin revealed no abnormal haemoglobin. Estimation of NADH-cytochrome b5 reductase could not be done due to the lack of laboratory facilities.

\section{QUESTION 4}

The patient was given ascorbic acid tablets (500 mg) twice daily and cyanosis disappeared within a week; it reappeared on cessation of the treatment. However, since the patient was clinically asymptomatic, no further treatment was given and the patient was reassured.

\section{Discussion}

Methaemoglobinaemia is a clinical condition in which more than $1 \%$ of haemoglobin is oxidised to methaemoglobin. It manifests as cyanosis when levels of methaemoglobin are more than $10 \%(1.5 \mathrm{~g} / \mathrm{dl})$. Presence of cyanosis from birth without clubbing distinguishes this condition from congenital cyanotic disease.

Methaemoglobin results when the normally reduced ferrous iron in the heme molecule is oxidised to the ferric state. This oxidation results in an inability of the heme molecule to reversibly bind oxygen. Normally, the ferrous iron of haemoglobin is oxidised slowly to methaemoglobin at a rate of about 3\% per day. Under physiologic conditions, the red cell can reduce methaemoglobin back to haemoglobin by the action of NADH-cytochrome b5 reductase (methaemoglobin reductase). ${ }^{3}$ This reaction utilises flavin-containing cytochrome b5 as an electron-carrying intermediate between $\mathrm{NADH}$ (derived from glycolysis) and methaemoglobin as shown below: 
$\mathrm{NADH}+(\mathrm{Ox})$ cyto b5 $\left(\mathrm{Fe}^{3+}\right) \rightarrow \mathrm{NAD}+(\mathrm{R})$ cyto b5 $\left(\mathrm{Fe}^{2+}\right)$

(R) cyto b5 $\left(\mathrm{Fe}^{2+}\right)+$ metHb $\left(\mathrm{Fe}^{3+}\right) \rightarrow(\mathrm{Ox})$ cyto b5 $\left(\mathrm{Fe}^{3+}\right)+\mathrm{Hb}\left(\mathrm{Fe}^{2+}\right)$

Besides the major cytochrome b5 reductase enzyme system, minor pathways to reduce methaemoglobin into haemoglobin are also present in the body. NADPH-methaemoglobin reductase reduces flavin in the presence of $\mathrm{NADPH}$, and reduced flavin further reduces methaemoglobin. This reductase is not essential and is probably responsible for only $5 \%$ of methaemoglobin reduction. ${ }^{3}$ This enzyme, however, is important in patients with hereditary methaemoglobinaemia since it reduces methaemoglobin rapidly in the presence of methylene blue. In addition to these enzymatic pathways, ascorbic acid and glutathione can reduce methaemoglobin directly but quantitatively are not very important, accounting for a very small amount of the methaemoglobin reduction.

Methaemoglobinaemia may be hereditary or acquired (box 2). Hereditary methaemoglobinaemia is a very rare condition. It has been reported among Navajo and Alaskan Indians, Cubans, Puerto Ricans, North Africans, Arabs, Hindus, Chinese, Japanese, Siberians and African-Americans. ${ }^{4}$ Around 500 cases of inherited methaemoglobinaemia have been reported in the literature, and most of the reports are descriptions of sibships derived from inbred populations. Hereditary methaemoglobinaemia is due to either the enzyme deficiency or an abnormality of haemoglobin in molecular structure, ie, haemoglobin $\mathrm{M}$ and unstable haemoglobins. Very rarely, it can occur due to deficiency of cytochrome b5 itself. Hereditary methaemoglobinaemia due to the deficiency of NADH-cytochrome b5 reductase is an autosomal recessive disorder. Therefore, patients who are heterozygotes for the deficiency of cytochrome b5 reductase do not have any cyanosis as the enzyme activity is approximately $50 \%$. Patients homozygotes for the enzyme deficiency are usually asymptomatic

\section{Causes of methaemoglobinaemia}

Hereditary

- NADH cytochrome b5 reductase deficiency

- M haemoglobin

- unstable haemoglobin

Acquired (drug-induced or toxin-induced)

- analgesic/antipyretics: acetanilid, phenacetin

- antimicrobials/antiseptics: dapsone, chloroquine, sulphonamides, phenazopyridine,

p-aminosalicylic acid

- vasodilators: amylnitrite, nitroglycerine, nitroprusside

- local anaesthetics: benzocaine, lignocaine, prilocaine

- surface-acting agents: silver nitrate, aniline dyes, mafenide acetate

- miscellaneous agents: nitric oxide, chlorate salts, nitrites, nitrobenzene, metoclopramide, potassium permanganate except for central cyanosis. These patients have normal life expectancy unless the methaemoglobin level is above $35-40 \%$. Clinically, three phenotypes have been reported. ${ }^{5}$ Type I is a red cell type with mild cyanosis due to deficiency of cytochrome b5 reductase in red cells only. Type II is known as a generalised type with deficiency of the enzyme in various tissues resulting in severe cyanosis and mental retardation with other neurologic features. Type III is a haematopoietic phenotype with deficiency of the enzyme in red cells, leukocytes and platelets, without mental retardation. Patients with haemoglobin $M$ are cyanotic but otherwise asymptomatic. Cyanosis may appear at birth or later in life depending upon the subunit of haemoglobin affected by mutation. In haemoglobin $M$, methaemoglobin is relatively resistant to the reducing system of the red cell. Some patients with unstable haemoglobin variants show an elevated level of methaemoglobin. However, methaemoglobinaemia does not contribute significantly to the clinical picture, since red cell haemolysis is dominant. Methaemoglobinaemia in these patients occurs when they are exposed to any oxidative stress. ${ }^{3}$

Acquired methaemoglobinaemia is caused by a wide variety of drugs and toxins (box 2) that result in direct oxidation of the ferrous ion in the heme. ${ }^{67}$ Infants below the age of 4 months are more susceptible to acquired toxin-induced methaemoglobinaemia due to a lower concentration of NADH cytochrome b5 reductase.

Manifestations of methaemoglobinaemia are purely the result of a decreased oxygencarrying capacity of the blood and depend on the concentration of methaemoglobin in blood (table). Symptoms due to hypoxia appear only if methaemoglobin levels in blood increase above $35 \%$. Patients with methaemoglobinaemia may manifest tachycardia, headache, dizziness, weakness, slate-blue colour, and terminally coma and death. ${ }^{7}$

The diagnosis of methaemoglobinaemia is based largely on history (including exposure to drugs and toxins), the characteristic central cyanosis unresponsive to oxygen administration, a normal $\mathrm{PaO}_{2}$, and a normal calculated oxygen saturation with a reduced measured oxygen saturation. A simple bedside test may be used to differentiate methaemoglobinaemia from cyanosis due to other causes. Dark-coloured blood from patients with cardiac or pulmonary disorders brightens rapidly after shaking in air. On the other hand, in methaemoglobinaemia, the blood remains dark-coloured even on shaking. Blood from patients with sulphaemoglobinaemia also

Table Manifestations of methaemoglobinaemia

\begin{tabular}{ll}
\hline $\begin{array}{l}\text { Methaemoglobin } \\
\text { levels (\%) }\end{array}$ & Clinical features \\
\hline $0-3$ & normal \\
$3-10$ & asymptomatic, no cyanosis \\
$10-35$ & aymptomatic but cyanotic \\
$35-70$ & cyanosis, symptoms due to tissue hypoxia \\
$>70$ & cyanosis, coma, death \\
\hline
\end{tabular}


remains dark on exposure to air, but this condition is very rare.

Patients with methaemoglobinaemia who have cyanosis and systemic manifestations need to be treated. In severe cases, intravenous methylene blue is required. Methylene blue is reduced to leucomethylene blue by NADPH. In turn, leucomethylene blue reduces methaemoglobin to haemoglobin. The recommended dose is $1-2 \mathrm{mg} / \mathrm{kg}$ of $1 \%$ solution administered over 5 minutes and the same dose may be repeated in one hour if symptoms of hypoxia persist. ${ }^{7}$ Cumulative doses of methylene blue exceeding $7 \mathrm{mg} / \mathrm{kg}$ may cause dyspnoea, chest pain, tremor, cyanosis and haemolysis. As the efficacy of methylene blue depends on adequate amounts of NADPH, care should be taken to exclude glucose-6-phosphate dehydrogenase (G6PD) deficiency. Methylene blue can produce methaemoglobinaemia in patients who are G6PD deficient. Due to its slow action, ascorbic acid is not recommended as

1 Eisenkraft JB. Pulse oximeter desaturation due to methaemoglobinemia. Anaesthesiology 1988;68:279-82.

2 Oesenberg B. Pulse oximetry in methaemoglobinemia. Anaesthesia 1990;45:56.

3 Mansouri A, Lurie AA. Concise review: methemoglobinemia. Am f Hematol 1993;42:7-12.

4 Lukens JN. Methaemoglobinemia and other disorders accompanied by cyanosis. In: Lee GR, Paraskevas F, Foerster J, Greer JP, Lukens J, Rodgers GM, eds. Wintrobe's Clinical hematology. Baltimore: Williams \& Wilkins, 1999; pp 1046-55. the only method of treatment in toxic methaemoglobinemia. Exchange transfusion may be required in severe cases not responding to methylene blue, when G6PD deficiency precludes use of methylene blue, or in case of aniline poisoning. Since patients with congenital $\mathrm{NADH}$-cytochrome b5 reductase deficiency are usually asymptomatic except for cyanosis, no treatment is indicated; however, for cosmetic purposes, ascorbic acid may be administered. It has a direct reducing action on methaemoglobin. Reduction of cyanosis is appreciated clinically about 9 to 10 days after therapy with ascorbic acid. ${ }^{8}$ No treatment is available for methaemoglobinaemia due to $M$ haemoglobins.

\section{Final diagnosis}

Congenital methaemoglobinaemia.

Keywords: cyanosis; methaemoglobinaemia

5 Jaffe ER. Enzymopenic hereditary methaemoglobinemia: a clinical/biochemical classification. Blood Cells 1986;12:8190.

6 White CD, Weiss LD. Varying presentation of methaemoglobinemia: two cases. F Emerg Med 1991;9:45-9. 7 Hall AH, Kulig KK, Rumack BH. Drug and chemical induced methaemoglobinemia - clinical features and management. Med Toxicol 1986;1:253-60.

8 Bolyai JZ, Smith RP, Gray CT. Ascorbic acid and chemically induced methaemoglobinemia. Toxicol Appl Pharmacol 1972;21:176-85. 


\title{
A focal central nervous system mass in an AIDS patient with tuberculous meningitis
}

\author{
Miguel Martín-Luquero, Luis A Marcos, Natalia Freijanes, José Luis Pérez-Castrillón
}

A 36-year-old man who had been seropositive for human immunodeficiency virus (HIV) for 2 years and who had not undergone treatment, was admitted to the hospital. He reported fever and headache during the week prior to admission. His CD4 count was $26 \times 10^{6} / 1$. The results of the physical examination were unremarkable. Contrast-enhanced T-1 weighted magnetic resonance imaging (MRI) displayed basal meningeal involvement, but no evidence of a cerebral mass (figure 1). Cerebrospinal fluid (CSF) examination revealed 435 white blood cells $/ \mathrm{mm}^{3}$, with $60 \%$ neutrophils and $40 \%$ lymphocytes, glucose $40 \mathrm{mg} / \mathrm{dl}$, protein $199 \mathrm{mg} / \mathrm{dl}$ and adenosine deaminase $40 \mathrm{IU} / 1$. The fluid smears were negative for acid-fast bacilli and a fluid culture revealed Mycobacterium tuberculosis. The $M$ tuberculosis isolates were susceptible to isoniazid, rifampicin, ethambutol, and streptomycin. The patient received isoniazid (300 mg daily), rifampicin (600 mg daily), pyrazinamide (1500 mg daily) and ethambutol (1800 mg daily). Antiretroviral treatment with zidovudine and didanosine was initiated. The patient improved and was asymptomatic after 3 weeks.

One month later the fever re-appeared, the CD4 count was $42 \times 10^{6} / 1$, and the HIV viral load was 2525000 copies $/ \mathrm{ml}$. The patient also suffered from headaches and appeared lethargic. On physical examination he showed marked stiffness of the neck and left hemiparesis. Contrast-enhanced T-1 weighted MRI (figure 2) displayed a large mass with a hypo-intense centre in the perimesencephalic region.

Department of Internal Medicine, Hospital Rio Hortega, University of

Valladolid, Valladolid, Spain

M Martín-Luquero

L A Marcos

N Freijanes

J L Pérez-Castrillón

Correspondence to José Luis Pérez Castrillón, Department of Internal Medicine, Cardenal

Torquemada s/n, 47010

Valladolid, Spain

Accepted 26 April 1999

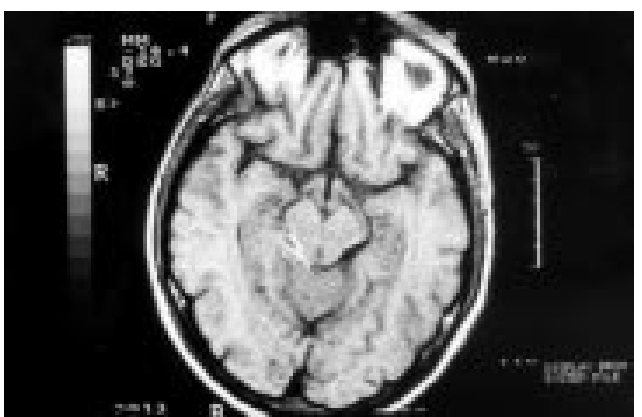

Figure 1 Contrast-enhanced T-1 weighted MRI at presentation

\section{Questions}

1 What is the differential diagnosis?

2 What is the clinical diagnosis?

3 What is the treatment?

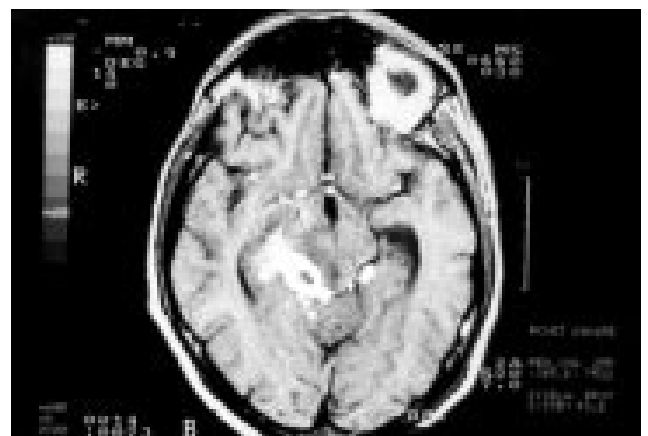

Figure 2 Contrast-enhanced T-1 weighted MRI one month later 


\section{Answers}

QUESTION 1

The causes of focal CNS mass lesion in a patient with acquired immune deficiency syndrome (AIDS) appear in the box.

\section{Causes of focal CNS mass lesion in AIDS}

- toxoplasmosis

- primary CNS lymphoma

- cryptococcosis (pseudocyst)

- tuberculosis (granuloma)

- syphilis (gumma)

- abscess (cryptococcal, tuberculous or bacterial)

QUESTION 2

The patient developed a mass lesion during adequate treatment for tuberculous meningitis. The MRI findings, in association with clinical and laboratory evidence of tuberculosis, suggest the paradoxical growth of an intracranial tuberculoma.

QUESTION 3

The optimal therapy is unknown due to the rarity of the disease. It should be treated empirically with at least four drugs. The value of adjunctive steroids cannot be determined. The patient was treated with isoniazid, rifampicin, pyrazinamide, ethambutol and dexamethasone. He recovered, and a subsequent MRI displayed a partial resolution of the tuberculoma (figure 3).

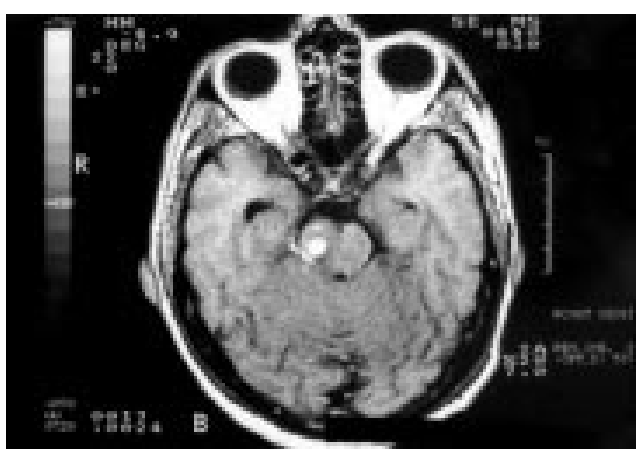

Figure 3 Contrast-enhanced T-1 weighted MRI after treatment

1 Berenguer J, Moreno S, Laguna F, et al. Tuberculous meningitis in patients with the human inmunodeficiency virus. $N$ Engl f Med 1992;326:668-72.

2 Leonard JM, Des Prez RM. Tuberculous meningitis. Infect Dis Clin North Am 1990;4:769-87

3 Teoh R, Humphries MJ, O'Mahony G. Symptomatic intracranial tuberculoma developing during treatment of tuberculosis: a report of 10 patients and review of the literature. $Q \mathcal{F} \mathrm{Med}$ 1987;63:449-60

4 Afghani B, Lieberman JM. Paradoxical enlargement or development of intracranial tuberculomas during therapy: case report and review. Clin Infect Dis 1994;19:1092-9.

\section{Discussion}

Tuberculosis has become another serious complication of AIDS, and the combination of both poses a significant clinical problem. ${ }^{1}$ Intracranial tuberculoma are caseous foci with fibrous encapsulation which develop in association with deep-seated tubercles and which are acquired during periods of haematogenous dissemination. ${ }^{2}$ They normally present with the symptoms and signs of a mass lesion. Headache, seizures, paralysis, and personality changes may be observed. CSF protein increase is common, but pleiocytosis is rare. The diagnosis is based on characteristic computed tomography or MRI findings in association with clinical and laboratory evidence of tuberculosis.

The patient displayed an unusual reaction during adequate treatment and his lesions worsened. The pathogenesis of paradoxical reactions remains unclear; they can occur during adequate treatment, and do not indicate the presence of drug-resistant organisms as a response to inadequate treatment. ${ }^{34}$ The most probable explanation may be an enhanced immune response to dying tubercle bacilli following the initiation of therapy. Seven cases of paradoxical expansion of intracranial tuberculoma in AIDS patients had been previously reported. ${ }^{5-7}$ The use of highly active antiretroviral therapy in HIV disease can result in some degree of immune reconstitution that may facilitate paradoxical expansion of tuberculoma. The immune status of our patient, however, was similar.

Our patient improved under treatment with corticosteroids, which are known to inhibit T-helper type 1 activity and tumour necrosis factor- $\alpha$ production and to stimulate T-helper type 2 cell activity, which may contribute to the regulation of immune response in paradoxical expansion. ${ }^{7}$ Surgical intervention should be considered when medical therapy fails or for relief of intracranial pressure.

Tuberculosis must be considered in the differential diagnosis of contrast-enhancing lesions of the central nervous system in AIDS patients, including those who have been treated for tuberculosis.

\section{Final diagnosis}

Paradoxical growth of intracranial tuberculoma during adequate treatment for tuberculous meningitis.

Keywords: intracranial tuberculoma; tuberculous meningitis; acquired immune deficiency syndrome

5 Ramdas K, Minamoto GY. Paradoxical presentation of intracranial tuberculomas after chemoterapy in a patient with AIDS. Clin Infect Dis 1994;19:793-4

6 Crump JA, Tyrer MJ, Lloyd-Owen SJ, Han LY, Lipman MC, Johnson MA. Miliary tuberculosis with paradoxical expansion of intracranial tuberculomas complicating human immunodeficiency virus infection in a patient receiving highly active antiretroviral therapy. Clin Infect Dis 1998;26: 1008-9

7 Lesprit P, Zagdanski A, De La Blanchardière A, et al. Cerebral tuberculosis in patients with the acquired immunodeficiency syndrome (AIDS). Report of 6 cases and review. Medicine 1997;76:423-31. 


\title{
Vomiting and constipation in an elderly diabetic woman
}

\author{
A Salih
}

An 80-year-old woman was admitted to William Harvey Hospital on 25 December 1997, with a 3-day history of generalised abdominal discomfort, intermittent vomiting and absolute constipation. Her medical history included hypertension, gall stones and insulin-dependent diabetes mellitus. There was no history of surgery.

On physical examination she was a moderately overweight woman, with mild dehydration, moderate abdominal distension, mild lower abdominal tenderness, normal bowel sounds and no evidence of inguinal or femoral herniae. Rectal examination revealed an empty rectum. Full blood count, urea and electrolytes, liver function test and serum amylase were normal. Her plain abdominal X-ray is shown in the figure.

William Harvey Hospital, Ashford, Kent TN24 0LZ, UK A Salih

Accepted 26 April 1999

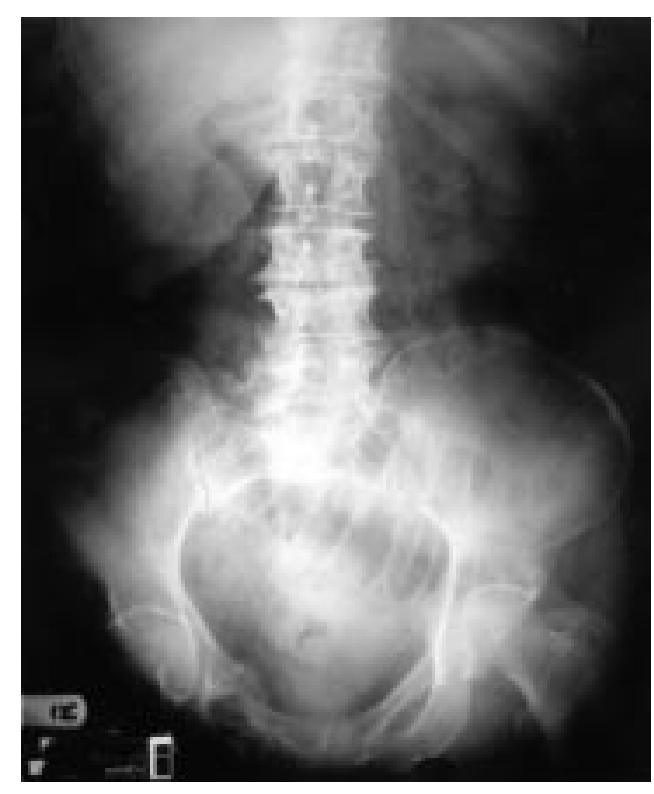

\section{Questions}

1 What does this plain abdominal X-ray show? 2 What is the most probable diagnosis?

3 How would you treat this patient? 


\section{Answers}

QUESTION 1

The plain abdominal X-ray shows dilated loops of small bowel and air in the biliary tree.

QUESTION 2

The diagnosis is small bowel obstruction caused by a large gall stone (gall stone ileus).

QUESTION 3

Emergency surgical exploration after optimal re-hydration, intestinal decompression and restoration of any electrolyte deficit. Surgical exploration in this case revealed a large gall stone impacted in the terminal ileum.

\section{Discussion}

Gall stone ileus is responsible for $1-4 \%$ of cases of mechanical bowel obstruction overall, but it accounts for $24 \%$ of bowel obstruction in patients over 70 years of age. ${ }^{1}$ The disease occurs more frequently in women than men, with a ratio between $4: 1$ and $16: 1$ according to the published literature. ${ }^{1-3}$ Eighty per cent of cases occur in elderly women in their seventh and eighth decade of life. ${ }^{2}$

Gall stone ileus is a mechanical intestinal obstruction caused by impaction of one or more gall stones within the bowel lumen. The impacted stone commonly originates in the gall bladder. Almost always the stone enters the gastrointestinal tract through a biliary-enteric fistula, usually through a cholecystoduodenal fistula and rarely through a cholecystocolonic fistula. ${ }^{4}$ In $80-90 \%$ of cases the stone passes spontaneously without symptoms. The most common site of impaction of the stone is the terminal ileum $(60 \%)$. Its occurs less commonly in the proximal ileum or distal jejunum, and rarely in the duodenum or colon. ${ }^{2}$

Clinical presentation is rarely specific and more than $30 \%$ of patients have no history of biliary symptoms. The median time between admission and the operation is $2-4$ days. $^{2}$

1 Hudspeth AS, McGuirt WF. Gall stone ileus, a continuing surgical problem. Arch Surg 1970;100:668-72.

2 Clavien PA, Richon J, Burgan S, Rohner A. Gall stone ileus. Br ₹ Surg 1990;77:737-42.

3 Deitz DM, Standge BA, Pinson CW, et al. Improving the outcome in gall stone ileus. Am f Surg 1986;151:572-6.
Mechanical intestinal obstruction with abdominal pain and vomiting is the most common clinical presentation. Concomitant geriatric diseases are present in up to $80-90 \%$ of cases. ${ }^{1}$

Rigler's triad of small bowel obstruction, ectopic gallstone and pneumobilia are classical findings on the plain supine abdominal X-ray. ${ }^{1}$ The presence of two signs has been considered pathognomonic, ${ }^{3}$ but is seen only in $30-35 \%$ of cases. ${ }^{1}$ Computed tomography, with its high contrast resolution, is reported to be more sensitive than plain abdominal radiography in detecting the three components of Rigler's triad. $^{5}$

Management of gall stone ileus is primarily surgical after restoration of the patient to optimal condition by hydration, intestinal decompression, and restoration of the electrolyte balance. ${ }^{3}$

Surgical treatment depends on the status of the patient and the experience of the surgeon. For the majority of surgeons, a one-stage procedure involving removal of the impacted stone by emergency laparotomy with enterolithotomy is the most acceptable approach. The rest of the bowel should be explored for the presence of another stone. Some surgeons, however, still prefer cholecystectomy and the repair of the fistula as a one-stage or two-stage procedure when the general condition permits, unless it has been clearly demonstrated that no stones remain in the gall bladder. ${ }^{2}$

The insidious nature of the clinical presentation, and the lack of specific signs of biliary disease, are responsible for delayed diagnosis and high mortality $(15 \%)$, which is five times that of other causes of bowel obstruction. ${ }^{1}$

\section{Final diagnosis}

Small bowel obstruction caused by a large gall stone (gall stone ileus).

Keywords: bowel obstruction; gall stone ileus; diabetes

\footnotetext{
4 Anseline P. Colonic gall stone ileus. Postgrad Med F 1981;57: $62-5$.

5 Leen GLS, Finlay M. CT diagnosis of gall stone ileus. Acta Radiol 1990;31:397-8.
} 